\title{
LA DEMOCRACIA COMO CONSTRUCCIÓN PERMANENTE
}

\author{
Democracy as a Work in Progress
}

\section{JOSÉ MIGUEL INSULZA}

Secretario General de la Organización de los Estados Americanos

La democracia es una construcción permanente. El debate sobre si ella se acerca o se aleja de lo realizable por las sociedades, es lo que debería nutrir el debate político. Hemos logrado en buena medida la democracia electoral, pero no hemos alcanzado todavía la democracia posible y por lo tanto exigible por los ciudadanos.

Existe un razonable acuerdo que por debajo de un cierto umbral carecemos de condiciones necesarias para el desenvolvimiento democrático. La existencia de elecciones libres y transparentes, el respeto de la libertad y seguridad de las personas, la defensa de la libre expresión, o un nivel adecuado de nutrición son algunos de los derechos indispensables que caracterizan el minimo de ciudadanía que debe estar presente en una democracia.

A lo largo de todo el continente se está dando un debate en el que coexisten diferentes matices acerca de los mejores caminos para el desarrollo democrático. Aún los resabios autoritarios que persisten pretenden bañarse en una supuesta legitimidad democrática. A pesar de la aparente paradoja, la aspiración general a la legitimidad de la democracia es una situación muy fértil para el debate sobre la naturaleza, alcance y limitaciones de la democracia latinoamericana.

El gran desafío de este debate es poder construir un terreno común sobre el cual avanzar en puntos de acuerdo, es decir, el núcleo fundamental desde donde la democracia se ramifica para encontrar su personalidad nacional en cada caso. La construcción de estos consensos requiere un enfoque plural para construir consensos mínimos, en lo social, político e institucional, que funcionen como una plataforma para el fortalecimiento de la democracia.

Este camino no es fácil y con frecuencia se encuentra bloqueado por prejuicios, generalizaciones y simplificaciones. A pesar de ello, el continente ha dado pasos significativos en la dirección correcta: todos los Estados miembros de la OEA aceptan y defienden la Carta Democrática Interamericana y existen iniciativas concretas para ampliar su alcance. La Carta Democrática Interamericana no es una receta universal de democracia, pero sí un gran aporte al núcleo central de consensos al que hacemos referencia.

La excepcional situación de la democracia latinoamericana requiere de contribuciones independientes al debate sobre la democracia posible. El camino transitado hasta ahora ha conseguido con mucho esfuerzo asegurar la democracia electoral en la región. La 
coyuntura actual apunta hacia la profundización de la democracia más allá de los mínimos imprescindibles. Estamos en un periodo donde la expansión de la democracia depende de la capacidad de las naciones latinoamericanas para producir la democracia exigible por los ciudadanos.

Esta democracia posible pasa por abordar de manera decidida el problema de la representación política y la participación electoral, por construir mecanismos para la separación efectiva de los poderes públicos y el fortalecimiento de la capacidad estatal para atender las demandas de una sociedad en transformación. También es necesaria una mayor capacidad de diseño de políticas públicas, pero sobre todo mayor capacidad de ejecución de dichas políticas, especialmente en áreas clave como las de fiscalidad, integración social y seguridad pública.

Si bien la democracia electoral constituye el mínimo imprescindible, la ampliación de la ciudadanía es hoy el nuevo umbral democrático sobre el cual debemos seguir trabajando para ampliar el horizonte de lo posible. Lograr la democracia de ciudadanía es, entonces, alcanzar el máximo realizable. Esto es, una situación de sostenibilidad democrática, de equilibrio estable, donde se asegura la persistencia y reproducción del sistema democrático por la vía de la legitimidad, de la satisfacción de las demandas sociales y de la creciente realización de los derechos.

José Miguel Insulza es Secretario General de la Organización de los Estados Americanos (OEA) desde el 26 de mayo del 2005. Es un reconocido político chileno que cuenta con una destacada trayectoria en el servicio público en su país. Abogado de profesión, Insulza tiene una licenciatura en Derecho de la Universidad de Chile, hizo estudios de postgrado en la Facultad Latinoamericana de Ciencias Sociales (FLACSO) y una maestría en Ciencia Política en la Universidad de Michigan. Fue profesor de Teoría Política en la Universidad de Chile y Ciencia Política en la Universidad Católica de Chile, hasta 1973. También hasta ese año sirvió como Asesor Político del Ministerio de Relaciones Exteriores y como Director de la Academia Diplomática.

Tras el golpe de Estado que llevó al poder al General Augusto Pinochet, inició un exilio que duró 15 años, primero en Roma (1974-1980) y luego en México (1981-1988), donde fue investigador y luego Director del Instituto de Estudios de Estados Unidos en el Centro de Investigación y Docencia Económica (CIDE), Profesor de la Universidad Autónoma de México, de la Universidad Iberoamericana y del Instituto de Estudios Diplomáticos. Regresó a Chile a principios de 1988 y se integró a la Concertación de Partidos por la Democracia. Miembro del Partido Socialista, ha ocupado un número importante de posiciones de alto nivel en los Gobiernos de la Concertación. Como Director de Asuntos Económicos Multilaterales del Ministerio de Relaciones Exteriores, Ministro de Relaciones Exteriores, Ministro Secretario General de la Presidencia, Ministro del Interior y Vicepresidente de la República por el Presidente Ricardo Lagos. Cuando dejó su cargo en mayo de 2005, Insulza había ejercido funciones a nivel ministerial por más de una década, el mayor período continuo para un ministro en la historia chilena. 